\title{
Erratum to: Thermal destruction of rice hull in air and nitrogen
}

\author{
Xue-Gang Chen $\cdot$ Shuang-Shuang Lv $\cdot$ \\ Ping-Ping Zhang $\cdot$ Lu Zhang $\cdot$ Ying Ye
}

Published online: 26 August 2011

(c) Akadémiai Kiadó, Budapest, Hungary 2011

Erratum to: J Therm Anal Calorim (2011)

104(3):1055-1062

DOI 10.1007/s10973-010-1201-2

Unfortunately the annotations in Fig. 6 and Fig. 7 are wrong as published in article with DOI 10.1007/s10973010-1201-2.
In the right pattern of Fig. 6, the "A600", “A750”, "A450", and "A300" should be corrected to "N600", "N750", "N450", and "N300". In Fig. 7 (left pattern), the annotations from top to down should be corrected to N750, N600, N450, $\mathrm{A} 750, \mathrm{~A} 600, \mathrm{~A} 450$, and $\mathrm{A} 300$. And the right pattern should be corrected to N750, A300, A450, A600, A750, N450, and N600 from top to down. The correct patterns are listed below.

The online version of the original article can be found under doi:10.1007/s10973-010-1201-2.

X.-G. Chen · L. Zhang · Y. Ye (ه)

Department of Ocean Science and Engineering,

Zhejiang University, Hangzhou 310028,

People's Republic of China

e-mail: chenxg83@gmail.com

S.-S. Lv

Department of Nonmetallic Research, Zhejiang Institute

of Geology \& Mineral Resources, Hangzhou 310007,

People's Republic of China

P.-P. Zhang

Second Institute of Oceanography, SOA, Hangzhou 310012,

People's Republic of China 
Fig. 6 Nitrogen adsorption (hollow patterned lines) and desorption curves (solid patterned lines) of RHA samples
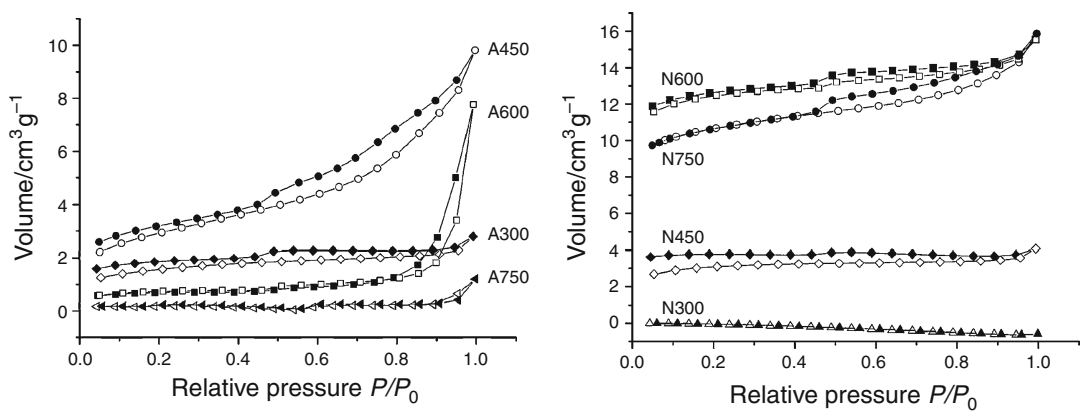

Fig. 7 Pore size distributions of RHA samples: left micropore, right mesopore
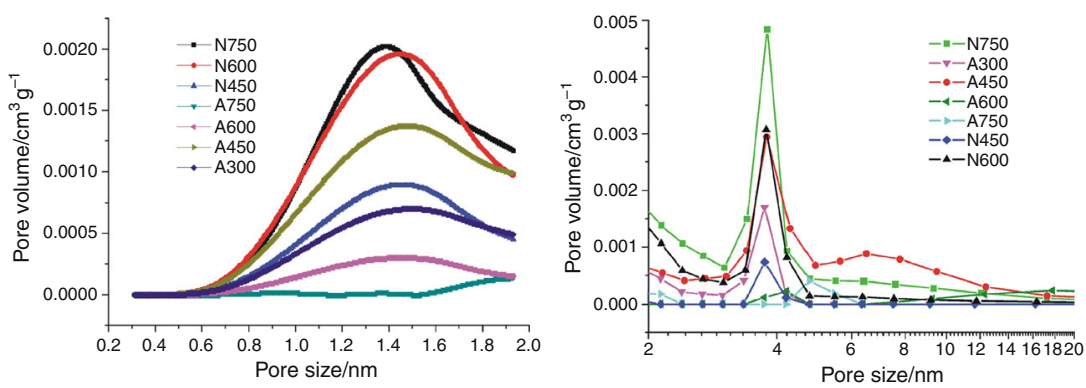